\title{
Community Potential in Massive Open Online Courses
}

\author{
$\mathrm{Ge} \mathrm{Mu}$ \\ School of Continuing Education \\ University of Electronic Science and Technology of China \\ Chengdu, China
}

\author{
Dimitris G. Assimakopoulos \\ Department of Economics \\ Emlyon Business School \\ Ecully Cedex, France 69134
}

\begin{abstract}
Since its emergence, massive open online courses (MOOCs) have promptly grasped the whole world's attention. It's an unprecedented phenomenon of one world-wide classroom. There also occurred a fierce world-wide debate around this new education mode questioning whether MOOCs could provide high-quality learning experience. This article surveys literatures about the birth and impact of MOOCs, arguments around this new education mode, and discusses the potential of utilizing MOOCs' discussion forums to better build learning communities, to improve social interaction and knowledge creation among MOOCs learners.
\end{abstract}

Keywords-MOOCs; social interaction; virtual community

\section{INTRODUCTION}

Massive Open Online Courses, or MOOCs, are webbased courses available for free to any participant from any place in the world [1]. The term MOOCs caused world-wide hype and discussion that New York Times named 2012 "The Year of the MOOC". It's interesting considering that distance education has a long history, while MOOCs are quite different from traditional online courses. Traditional online courses charge tuition, carry credit and limit enrollment to a few dozen, to ensure interaction with instructors, while the MOOCs are usually free, credit-less and massive [2].

The first MOOC in the world is generally considered to be "Connectivism and Connective Knowledge" (known as CCK08), an online course offered through the Learning Technologies Centre and Extended Education at the University of Manitoba by George Siemens and Stephen Downes in 2008 [3], [4]. This online course had 25 feepaying students on campus with around 2,200 other students from the general public who took the online class free of charge [5]. Though the term MOOC was then coined to describe CCK08, this kind of course and connectivism pedagogy remains on the radical fringe of higher education, and didn't catch much of the media's attention at that time.

In the fall of 2011, the University of Stanford offered a course on artificial intelligence (CS221), free and online. The instructors were Sebastian Thrun and Peter Norvig, two of the best known expert in the subject. This online course attracted 160,000 registered students from 190 countries. Although students would not get Stanford University grades or credits, 20,000 students successfully finished the course and received a statement of accomplishment from the instructors [6].

Since then, a range of MOOCs platforms have emerged and grown quickly. Udacity is a commercial start-up found by the authors of CS221 delivering similar massive free online courses. EdX is a nonprofit joint partnership between the Massachusetts Institute of Technology and Harvard University, which soon had 370,000 students in fall of 2012. Coursera, a for-profit MOOC provider founded in January 2012, reached more that 1.7 million students that year [2]. MOOCs are so widely discussed across all kinds of media, including vast amount of blogs and popular press, promotional material by commercial interests and articles by practitioners whose perspective is their own courses, that some described MOOCs as "the educational buzzword of 2012" [5] to reflect the widespread interest in the concept and its dominance of the news. Fierce world-wide debate around this new education mode: evidently, guidance from teachers and feedback from peers are both crucial for learning process, can MOOCs provide high quality learning as promised?

\section{PERSONALIZED AND SOCIALIZED LEARNING IN MOOCS}

Courses provided by mainstream MOOC platforms which attracted huge media attention are very different from CCK08. Online courses like CCK08 are usually referred to as connectivist MOOCs or cMOOCs [5], [6], which apply the principles of connectivism [7], a controversial learning theory still being refined and developed [8], [9]. On the other hand, newer type of massive open online courses were referred to as "AI-Stanford like courses" [6] or xMOOCs[5], which follow cognitive-behaviorist, individualist learning approaches. George Siemens points out that though cMOOCs and xMOOCs both take advantage of distributed networks to reflect changing educational practice, "differences exist in the underlying views of knowledge and learning that inform the different MOOC models" [10]. He says the cMOOCs model focuses on knowledge creation through online discussion, emphasizes "creation, creativity, autonomy, and social networked learning", while the xMOOCs model focuses on knowledge duplication and 
emphasizes "a more traditional learning approach through video presentations and short quizzes and testing" [11].

Can MOOCs provide personalized and socialized learning? Many believe that for cMOOCs, the answer is yes. For example, Kop [12] says "in connectivism, the starting point for learning occurs when knowledge is actuated through the process of a learner connecting to and feeding information into a learning community." McAuley [13] says it "integrates the connectivity of social networking, the facilitation of an acknowledged expert in a field of study, and a collection of freely accessible online resources."

But for the currently mainstream type of MOOCs, or xMOOCs, conflicting viewpoints are identified. There have been many criticisms of its instructional methods. People agree that MOOCs allow students alternative routes through material and automated feedbacks, but many argued that they do not provide a sense of being treated as an individual[14]. Critics say MOOCs students were put in a "very nonsocial media environment of quizzes, short writing tasks, and pretaped video lectures" [15], lacking the "possibility of building a meaningful student-to-student or student-toteacher interaction" [16]. Meanwhile, some researchers argued that these critiques "rely on generalizations about MOOCs without a sustained exploration of the spaces in such sites where an intellectual community develops" [17]. Other researchers believe that no matter whether or not an instructor intended to develop critical thinking or to promote interaction among students, it can still happen in the MOOC [18]; almost all MOOCs do enable some level of networked engagement, whether or not they scaffold it effectively[19].

\section{EXPLORE THE COMMUNITY POTENTIAL IN MOOCS}

The idea of community traditionally refers to groups formed with geography, professional field or administrative field and other specific fields as the dividing standards. Since the early 1990's, the internet has been used as an enabling technology for long-distance communication and interaction [20]. Due to the Internet's open architecture, users can surf the Internet to find information anytime and anywhere, or share their views and opinions on a specific topic under a borderless virtual network. This kind of information sharing and communication breaks through the limitation of the time and space, and makes communication and interaction between people become more frequent. It also provides a favorable environment for the development of computermediated communications which connect people everywhere, and accelerates the emergence of various new types of communities [20]. This new kind of community are different from traditional communities, in that the internet have extended the reach of human interactions beyond the geographical limitations of traditional communities [21], and are called online community, or virtual community.

Virtual communities are different from offline ones, as members of a virtual community don't necessarily live in the geographical near area (e.g. live in a same village), or attend same activities simultaneously (e.g. go to class together). But there are still similarities between virtual community created by the network technology and offline community. Both of them are formed by the social relations, allow members of the community to exchange information, share experience and support each other, and achieve a sense of belonging. Virtual community members don't quite feel the need to meet each other face to face, or to know each other's real name. Strangers in the real world can connect to the heart of the members of the virtual community through the computer and network so as to establish a long-term and stable relationship. The internet technology and people's same interests or common goals, is the base stone of the establishment and maintenance of virtual communities. People belong to a community because they feel the sense of identity and of belonging. This kind of sense of identity and belonging are formed after a certain time of understanding and communication and can strengthen the relationship between members[22].

Based on human's basic demands, Hagel [23] divide communities into four categories: transactional communities, interest communities, fantasy communities and relation communities. Adler [24] divide network communities into demographic community, professional community and personal interest community: Demographic community, which consist of the groups with the specific backgrounds, such as undergraduates, graduates and alumni. Professional community, which consists of specific technical staff, such as medical staff, software engineers and so on. Personal interest community, which consists of the people who form a group due to same interests, are attracted by the shared subjects. Virtual communities can also be divided into synchronous communities and asynchronous communities[25]. In a synchronous community, members can communicate with other members in real time, with chat room and other tools. On the other hand, in an asynchronous community, its members can't communicate with other members in real time, but interact through online message board, e-mail or other tools.

Education is one of the most important application areas of virtual community. Virtual communities with the basic purpose of learning and education are known as virtual learning community (VLCs). Applying the above taxonomy, the virtual learning communities in MOOCs can be categorized to asynchronous personal interest communities.

Despite the hype and speculation about MOOCs, empirical research that explores the realities of interacting and learning in MOOCs is in its infancy [26]. Some early studies are quite instructive. A 2013 survey[27] of 103 MOOC professors conducted by The Chronicle of Higher Education claimed that "it was not unusual for a professor to be drawn into the discussion forums". Clinnin [17] examined the Rhetorical Composing MOOC offered through Coursera, argues that by engaging in reciprocal educational exchanges with other students, students formed multilingual learning communities that enabled students to meet their individual learning objectives.

Though the mainstream MOOC platform Coursera's founder Andrew $\mathrm{Ng}$ described the online learning process in the massive open online courses as community-based 
engagement, considering the many existing criticism, it's evident that more works need to be done.

\section{CONCLUSION}

Community and social networking has the potential to be a very promising and vital component of MOOCs. Some researchers believe that the benefit of MOOCs lies in the spaces for engagement made possible by the course [18], the networked learning in MOOCs may "create ethos of distributed expertise, increased peer-to-peer participation, collaboration, and knowledge generation" [19], and that the communities in MOOCs would be of great importance for learning, assessment and credentialing[28]. To realize the community potential in MOOCs, we must better understand factors affecting learners' engagements, and the structure and dynamic of learners' social network in MOOCs. Future research could look further into the real data generated from mainstream MOOCs platforms, especially their online discussion forums employed by each courses. These findings will help us improving social interaction between teachers and learners, stimulating knowledge creation among MOOCs learners, and building learning communities that would benefit the massive group of learners beyond physical boundaries.

\section{REFERENCES}

[1] Dave Cormier, George Siemens. The Open Course: Through the Open Door--Open Courses as Research, Learning, and Engagement[J]. Educause Review, 2010, 45(4): 30.

[2] Laura Pappano. The Year of the MOOC[J]. The New York Times, 2012, 2(12): 2012.

[3] Stephen Downes. Places to go: Connectivism \& connective knowledge[J]. Innovate: Journal of Online Education, 2008, 5(1): 6.

[4] Tharindu Rekha Liyanagunawardena, Andrew Alexandar Adams, Shirley Ann Williams. MOOCs: A systematic study of the published literature 2008-2012[J]. The International Review of Research in Open and Distributed Learning, 2013, 14(3): 202-227.

[5] John Daniel. Making sense of MOOCs: Musings in a maze of myth, paradox and possibility[J]. Journal of interactive Media in education, 2012, 2012(3): Art. 18.

[6] Osvaldo Rodriguez. MOOCs and the AI-Stanford Like Courses: Two Successful and Distinct Course Formats for Massive Open Online Courses[J]. European Journal of Open, Distance and E-Learning, 2012,

[7] George Siemens. Connectivism: A learning theory for the digital age [J]. International Journal of Instructional Technology and Distance Learning, 2005, 2(1)

[8] Frances Bell. Connectivism: Its place in theory-informed research and innovation in technology-enabled learning $[\mathrm{J}]$. The International Review Of Research In Open And Distributed Learning, 2010, 12(3): 98-118.

[9] Tony Bates. Teaching in a digital age[J]. Glokalde, 2015, 1(3)

[10] George Siemens, 'What is the theory that underpins our moocs', Blog Elearnspace, <http://www.elearnspace.org/blog/2012/06/03/what-is-the-theorythat-underpins-our-moocs/>.

[11] —, 'MOOCs are really a platform'2012) <http://www.elearnspace.org/blog/2012/07/25/moocs-are-really-aplatform/>.

[12] Rita Kop, Adrian Hill. Connectivism: Learning theory of the future or vestige of the past?[J]. The International Review of Research in Open and Distributed Learning, 2008, 9(3)
[13] Alexander McAuley, Bonnie Stewart, George Siemens, etc., 'The MOOC model for digital practice'2010) $<$ http://davecormier.com/edblog/wpcontent/uploads/MOOC_Final.pdf $>$.

[14] Tony Bates, 'What's right and what's wrong about Coursera-style MOOCs'2012) <http://www.tonybates.ca/2012/08/05/whats-rightand-whats-wrong-about-coursera-style-moocs/>.

[15] Jeff Rice. What I learned in MOOC[J]. College Composition and Communication, 2013, 64(4): 695-704.

[16] Matt Levinson, 'Where MOOCs miss the mark: The student-teacher relationship', Edutopia, (2013) <http://www.edutopia.org/blog/whereMOOCs-miss-the-mark-matt-levinson>

[17] Kaitlin Clinnin. Redefining the MOOC: Examining the multilingual and community potential of massive online courses[J]. Journal of Global Literacies, Technologies, and Emerging Pedagogies, 2014, 2(3)

[18] Maha Bali. MOOC pedagogy: gleaning good practice from existing MOOCs[J]. MERLOT. Journal of Online Learning and Teaching, 2014, 10(1): 44-56.

[19] Bonnie Stewart. Massiveness+ openness= new literacies of participation[J]. MERLOT Journal of Online Learning and Teaching, 2013, 9(2): 228-238.

[20] Dimitris Assimakopoulos, Jie Yan. An innovative model of a computer-mediated professional community: China software developer net[J]. International Journal of Technology Management, 2008, 43(1): 238-251.

[21] Etienne Wenger. Communities of practice: A brief introduction[J]. 2011,

[22] Howard Rheingold, 'A slice of life in my virtual community', in Global networks, ed. by M. Harasim LindaMIT Press, 1993), pp. 5780.

[23] John Hagel, Arthur Armstrong. Net gain: Expanding markets through virtual communities[M]. Harvard Business Press, 1997.

[24] P Richard Adler, J Anthony Christopher. Internet community primer overview and business opportunities[J]. http://www.digitalplaces.biz/pages/primer_00_toc.html, 1998,

[25] Anita Blanchard. Virtual Behavior Settings: An Application of Behavior Setting Theories to Virtual Communities[J]. Journal of Computer-Mediated Communication, 2004, 9(2)

[26] Nabeel Gillani, Rebecca Eynon, Michael Osborne, et al. Communication communities in MOOCs[J]. arXiv preprint arXiv:1403.4640, 2014,

[27] Steve Kolowich. The professors who make the MOOCs[J]. Chronicle of Higher Education, 2013, 59(28): A20-A23.

[28] Stephen Downes, 'The rise of MOOCs'2012) <http://www.downes.ca/post/57911>. 